\title{
The mistakes and the misconceptions of the eighth grade students on the subject of angles
}

\author{
Çağrı Biber ${ }^{1}$, Abdulkadir Tuna ${ }^{1}$, Samet Korkmaz ${ }^{1}$ \\ Kastamonu University, Educational Faculty, Mathematics Education, Kastamonu, Turkey \\ For correspondance: atuna@kastamonu.edu.tr
}

\begin{abstract}
The purpose of this study was to determine the learning levels, mistakes, and misconceptions of the $8^{\text {th }}$ grade students on the subject of "angles in geometry" as well as the possible reasons for these situations. Research sample consisted of 30 students attending the $8^{\text {th }}$ grade of a middle school located in the central district of a northern province of Turkey during the $2012-2013$ academic year. 4 open-ended questions were used in this study. Firstly, the answers given were divided into two: correct and incorrect. Then, incorrect answers were split into sub-categories and tabulated. According to the results of the study, (1) students paid attention to the physical appearances of geometric figures alone without taking into consideration their geometric properties; (2) although they detected some geometric properties of figures, they failed to associate these properties with other knowledge required for solution; (3) they generalized a property that was valid for only a specific condition over different situations; (4) and they did not fully comprehend the concept of parallelism on the subject of angles.
\end{abstract}

Keywords: Mathematics Education, Geometry, Misconceptions

\section{Introduction}

Geometry is a branch of mathematics concerned with point, straight line, plane, plane figures, space, spatial figures, and the relations between them besides the measures of geometric figures including length, angle, area, volume, etc. (Baykul, 1999). Serving as a bridge between events in daily life and mathematical concepts, geometry has a crucial importance for mathematics learning. National Council of Teachers of Mathematics in the USA (NCTM, 2000) published a book where they set the principles and standards of school mathematics. This book highlights the importance of geometry, and stresses that geometry improves the reasoning and proving skills of students. According to the NCTM standards, geometry lesson teaches students about geometric figures and structures as well as their characteristic features and relations with one another.

Although geometric concepts have a visual aspect, students consider them difficult to learn (NCTM, 1989). Baki (2004) suggests that conceptual knowledge refers to not only recognizing a concept or knowing the definition and name of a concept, but also seeing the mutual transitions and relations among concepts. Conceptual knowledge is associated with relations among a great variety of different concepts. If we treat conceptual knowledge as a chain, each ring of this chain contains a piece of knowledge. Similarly, if we assume that all geometry subjects which are strictly linked to one another make up a chain, the subject of "angles", which is the basis of geometry, is the most essential ring of this chain. Almost every subject of geometry requires a good knowledge of angle, which is one of the basic concepts of geometry. Any student who has not adequately comprehended basic geometric concepts will not understand and succeed in the subsequent subjects of geometry, either. This may reduce the achievement of an individual in both school life and daily life (Alkan and Altun, 1998).

Geometry is used for solving problems associated with other branches of mathematics besides its usage for solving problems about daily life and utilization in other disciplines than mathematics (e.g. art) for different purposes. Although not many statistical studies have been conducted on this subject among primary education and secondary education students in Turkey, it is evident that students have a big difficulty in understanding geometry (Yılmaz et al., 2005).

There are many studies showing that students have many difficulties in understanding geometry, which is a crucial component of mathematics education (Mayberry, 1983; Mitchelmore, 1997; Prescott, Mitchelmore, and White, 2002; Thirumurthy, 2003; Van Hiele, 1986; Van Hiele-Geldof, 
1984). According to Mayberry (1983), students mostly learn geometric concepts based on a rotelearning approach. The properties, scopes, associations, and meanings contained in geometric expressions cannot be taught satisfactorily. Clements and Battista (1992) indicated the reasons for students' misconceptions about geometric concepts as follows: students do not understand subjects sufficiently, they overgeneralize specific rules about geometric expressions, they mostly learn by rote, and they cannot understand concepts exactly.

If a student has a misconception prior to learning a subject, this may prevent him/her from learning the new subject properly, thereby leading to new misconceptions. The related literature reveals that students learn new topics by combining new knowledge with their preliminary knowledge. Thus, teaching activities should be planned by considering the knowledge and misconceptions of students. For that, the existing knowledge and the misconceptions (if any) of students should be determined (Gilbert, Osborne, and Fensham, 1982).

Literature review shows that there are not many studies investigating the misconceptions held by students on the subject of "angles in geometry". While some studies deal with the difficulties encountered in applying the subject of angles to solid geometry (Kopelman 1996), some others focus on the difficulties experienced in definitions based on angle measures (Matos, 1994). The present study investigated the mistakes and the misconceptions of primary education $8^{\text {th }}$ grade students on the subject of "angles in geometry".

The significance of this study is that it determined the mistakes and the misconceptions experienced by students during the learning of the subject of "angles in geometry" as well as the reasons for such mistakes and misconceptions, and revealed the importance of taking into consideration these mistakes and misconceptions while giving a mathematics lesson.

Since there were not many studies focusing on misconceptions in geometry in Turkey, it was deemed significant to investigate misconceptions through open-ended questions by taking into consideration the manners of learning the subject of angles along with different contents (parallel lines, triangles, etc.). In the present study, the word "mistake" was used for referring to calculation errors made by students during problem-solving while the word "misconception" was used for indicating the conceptual obstacles making learning difficult.

Concepts about the subject of "angles" start to be presented to students in the third grade. These concepts are covered in the following grades, too (e.g. angles in parallel lines are taught in the $7^{\text {th }}$ grade, and angles in triangles are taught in the $8^{\text {th }}$ grade). When students learn wrongly the concepts about the aforesaid subjects in these grades, they may fall into the same errors in their future learning lives. The purpose of this study was to determine the learning levels, mistakes, and misconceptions of the $8^{\text {th }}$ grade students on the subject of "angles in geometry" as well as the possible reasons for these situations.

\section{Method}

\section{Data Collection Tool}

In this study, 4 open-ended questions were used for examining the learning levels of students on the subject of "angles in geometry". The questions were prepared both based on the related literature and by receiving support from a mathematics educator. Normally, whether the problems contained in a data collection tool are fit for measurement purpose and represent the domain which is intended to be measured is determined based on "expert opinion" (Karasar, 1995). In this study, a group of experts firstly examined measurement purposes, and carried out the content analyses required by those purposes. Then, the group of experts discussed whether the problems prepared would represent those purposes and contents.

\section{Study Group}

Questions were prepared in parallel with one another in order to understand whether mistakes resulted from calculation errors or misconceptions. These questions were administered to a total of 30 students attending the $8^{\text {th }}$ grade of a middle school located in the central district of a northern province of Turkey during the $2012-2013$ academic year.

\section{Data Analysis}

The answer sheets of students were coded as follows: $S_{1}, S_{2}, S_{3}, \ldots, S_{30}$. The solutions of students were examined under three categories: correct, incorrect, and no solution. Moreover, those solutions 
which were considered incorrect were examined in detail to focus on the reasons with which mistakes might be associated. For data analysis purposes, two mathematics education experts independently coded data by using the coding list. Inter-coder reliability was ensured as the percentage of correspondence between two coders was found to be $90 \%$ according to the formula suggested by Miles and Huberman (1994). The items in which the coders disagreed were revised so that a joint decision could be made. Descriptive statistical techniques (percentage/frequency) were used for analyzing the data acquired from the related test.

\section{Findings}

This section provides the findings of the study and relevant comments on these findings. Each question was examined separately, and the acquired data were presented in tables.

\section{Question 1:}

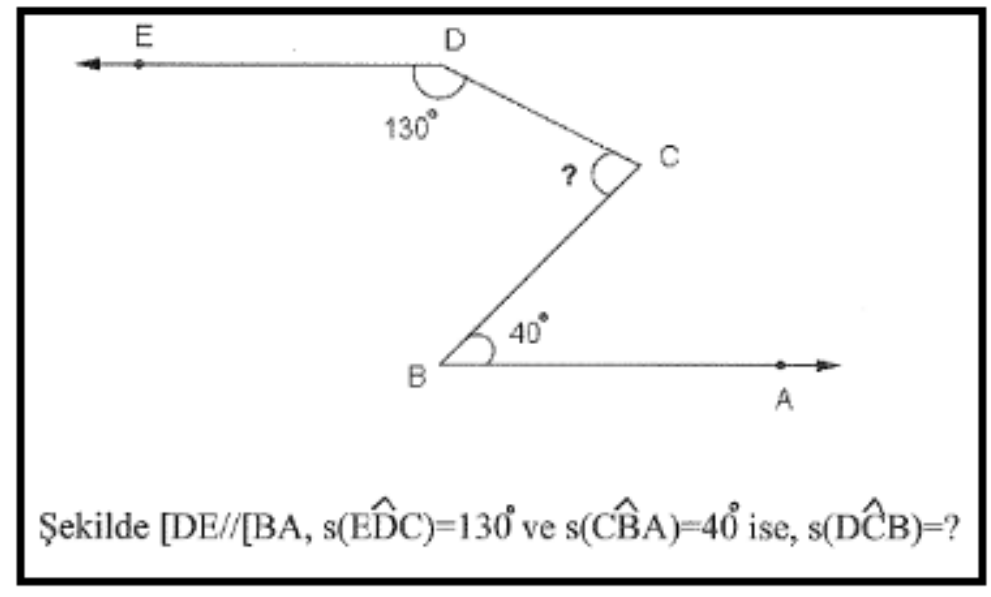

Figure 1. The $1^{\text {st }}$ Question

With this question, it was aimed at determining what sort of mistakes students made while using their knowledge about "parallelism", "the sum of supplementary angles is $180^{\circ}$ ", and "the sum of interior angles of a triangle is $180^{\circ \prime \prime}$.

Table 1 provides an analysis of the answers given by students to the $1^{\text {st }}$ question.

Table 1. The Evaluation of Student Solutions for the $1^{\text {st }}$ Question

\begin{tabular}{|c||c||c||c|}
\hline Question 1 & Correct & Incorrect & No Solution \\
\hline $\begin{array}{c}\text { The Number of } \\
\text { Students }\end{array}$ & 17 & 13 & - \\
\hline$\%$ & $57 \%$ & $43 \%$ & - \\
\hline
\end{tabular}

( ${ }^{*}$ Percentages are approximate values.)

According to the table 1, 43\% of students solved this question wrongly. Based on the examination of the incorrect answers given, it was realized that students i) did not know what the third line intersecting two parallel lines meant, and ii) paid attention to the physical appearance of the geometric figure alone without taking into consideration its geometric properties. These findings and 2 sample student solutions about each finding are presented in table 2 . 
Table 2. The analysis of the wrong solutions observed in the $1^{\text {st }}$ question

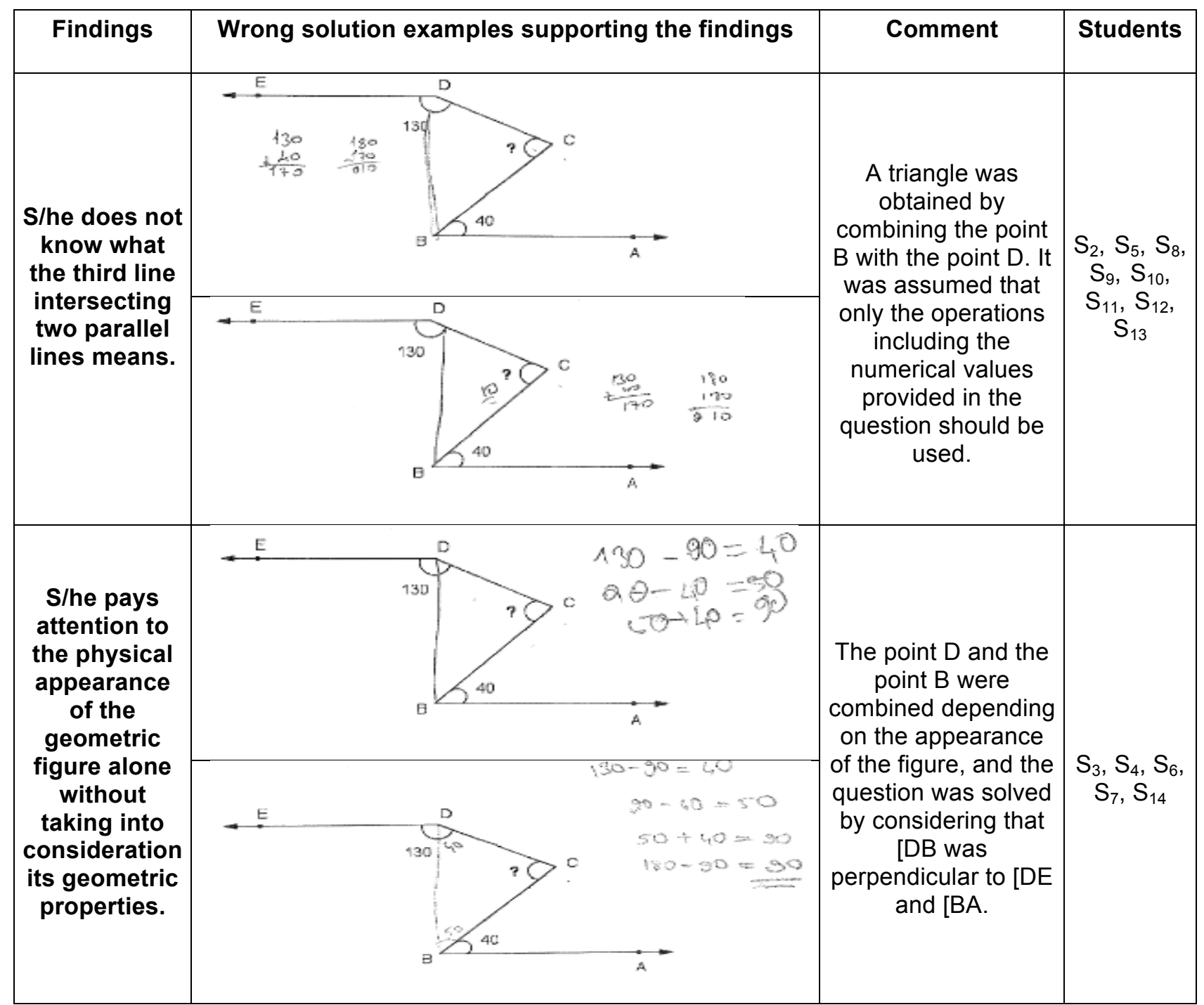

\section{Question 2:}

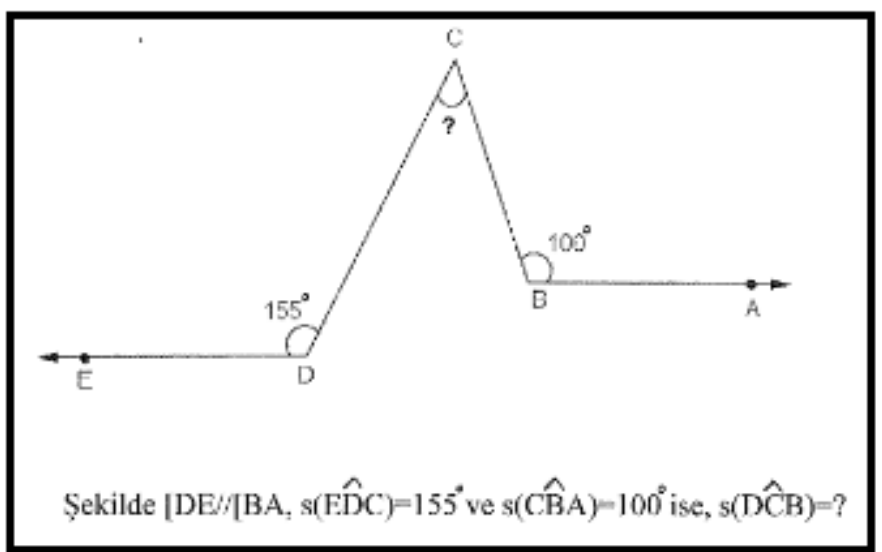

Figure 2. The $2^{\text {nd }}$ Question

In this question, students were expected to use their knowledge about "parallelism", "the sum of supplementary angles is $180^{\circ \prime}$, and "the sum of interior angles of a triangle is $180^{\circ \prime}$. 
Table 3 provides an analysis of the answers given by students to the $2^{\text {nd }}$ question.

Table 3. The Evaluation of Student Solutions for the $2^{\text {nd }}$ Question

\begin{tabular}{|c|c|c|c|}
\hline Question 2 & Correct & Incorrect & No Solution \\
\hline $\begin{array}{l}\text { The Number } \\
\text { of Students }\end{array}$ & 19 & 11 & - \\
\hline$\%$ & $63 \%$ & $37 \%$ & - \\
\hline
\end{tabular}

("Percentages are approximate values.)

According to the table 3,37\% of students solved this question wrongly. Based on the examination of the incorrect answers given, it was realized that students i) did not know what the third line intersecting two parallel lines meant, and ii) paid attention to the physical appearance of the geometric figure alone without taking into consideration its geometric properties, as in the first question. These findings and 2 sample student solutions about each finding are presented in table 4 .

Table 4. The analysis of the wrong solutions observed in the $2^{\text {nd }}$ question

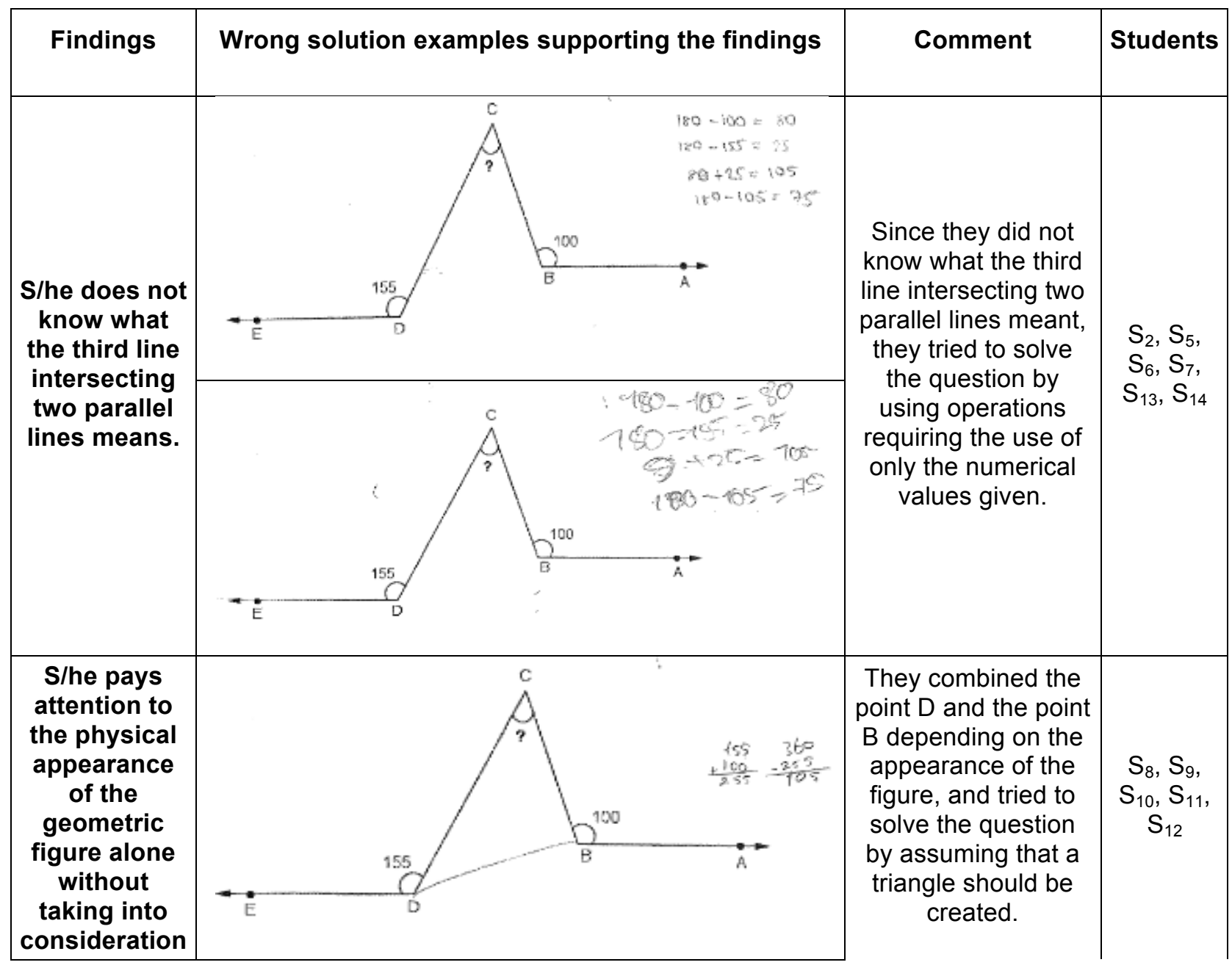




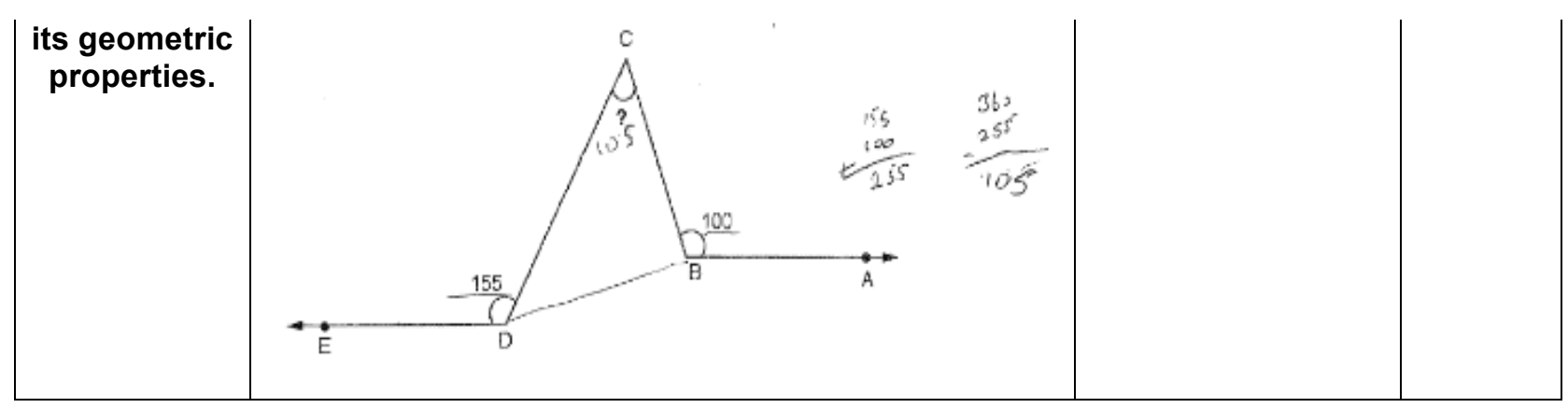

As can be seen in the figure 1 and figure 2 , the $1^{\text {st }}$ and the $2^{\text {nd }}$ questions were similar, thus similar knowledge should be used for solving them. Based on the examination of the answers given by students to these questions, it was seen that the same students repeated similar mistakes while answering the above-mentioned questions.

With the questions above, it was seen that students had mistakes about what the third line intersecting two parallel lines meant and the geometric properties of figures. The fact that the same students made these mistakes in similar questions demonstrates that they had misconceptions on those subjects.

\section{Question 3:}

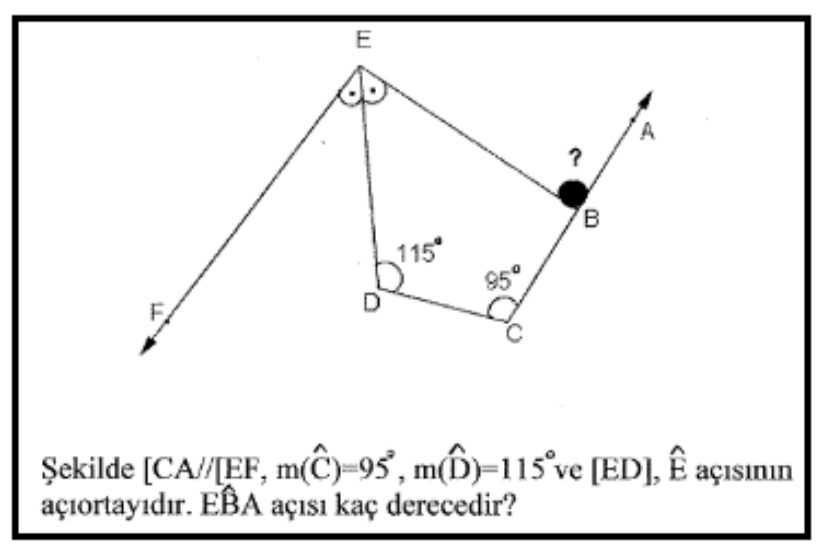

Figure 3. The $3^{\text {rd }}$ Question

In this question, students were expected to use their knowledge about "parallelism", "the sum of supplementary angles is $180^{\circ}$ ", "the sum of interior angles of a triangle is $180^{\circ}$ ", or "the sum of interior angles of a quadrilateral is $360^{\mathrm{o}^{\prime \prime}}$.

The form of the $3^{\text {rd }}$ question was more complicated in comparison to the $1^{\text {st }}$ and $2^{\text {nd }}$ questions. In this way, the mistakes of students were examined in a question that required the use of similar knowledge, but had a more complicated appearance.

Table 5 provides an analysis of the answers given by students to the 3rd question.

Table 5. The Evaluation of Student Solutions for the 3rd Question

\begin{tabular}{|c|c|c|c|}
\hline Question & Correct & Incorrect & No Solution \\
\hline $\begin{array}{l}\text { The Number } \\
\text { of Students }\end{array}$ & 12 & 15 & 3 \\
\hline$\%$ & $40 \%$ & $50 \%$ & $10 \%$ \\
\hline
\end{tabular}


According to the table 5, 50\% of students solved this question wrongly. Based on the examination of the incorrect answers given, it was realized that students i) did not know what the third line intersecting two parallel lines meant, and ii) detected some geometric properties of the figure, but failed to associate these properties with other knowledge required for solution.

To make the mistakes made by students clearer, the above-mentioned findings and 2 sample student solutions about each finding are presented in table 6 .

Table 6. The analysis of the wrong solutions observed in the $3^{\text {rd }}$ question

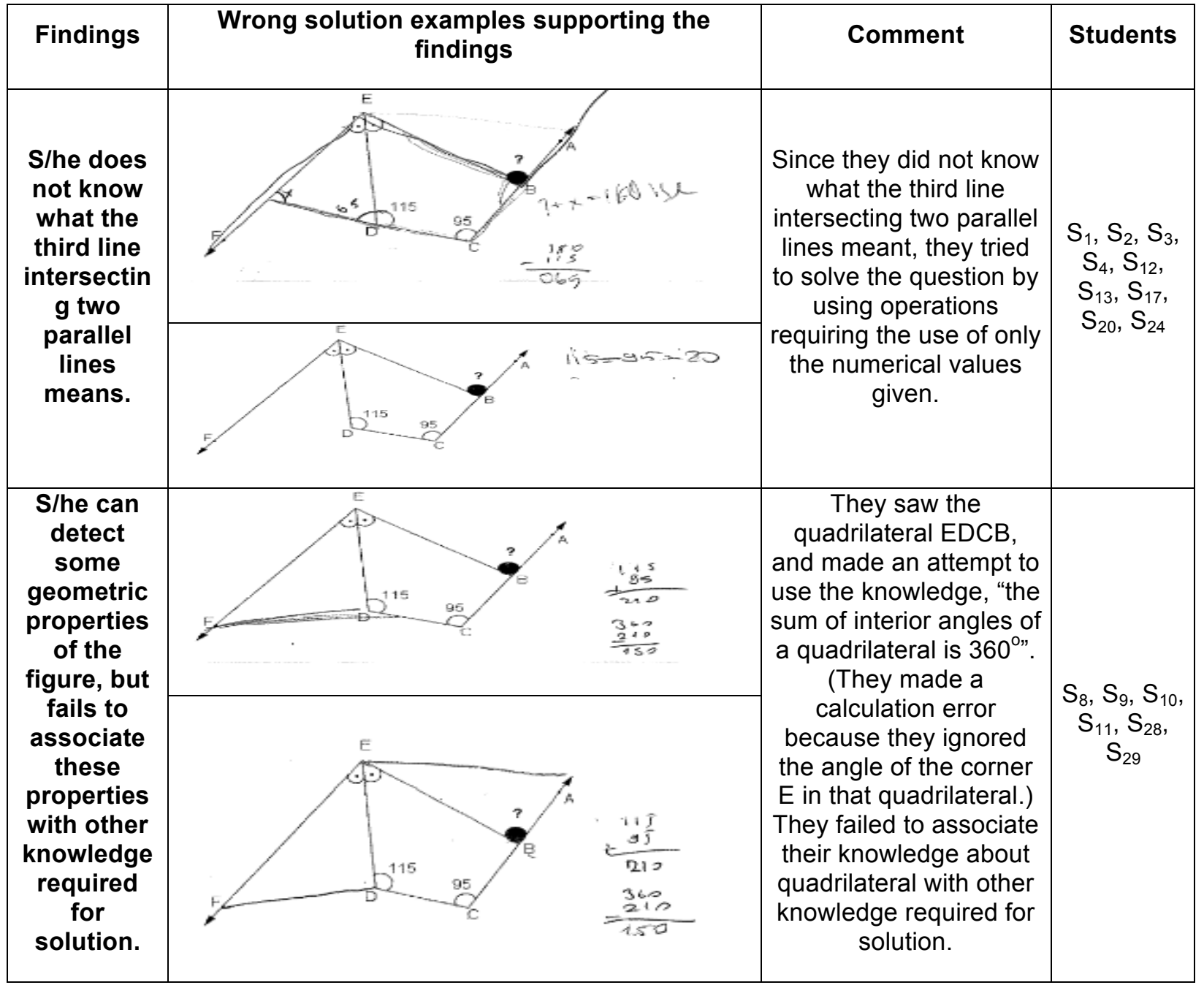

\section{Question 4:}

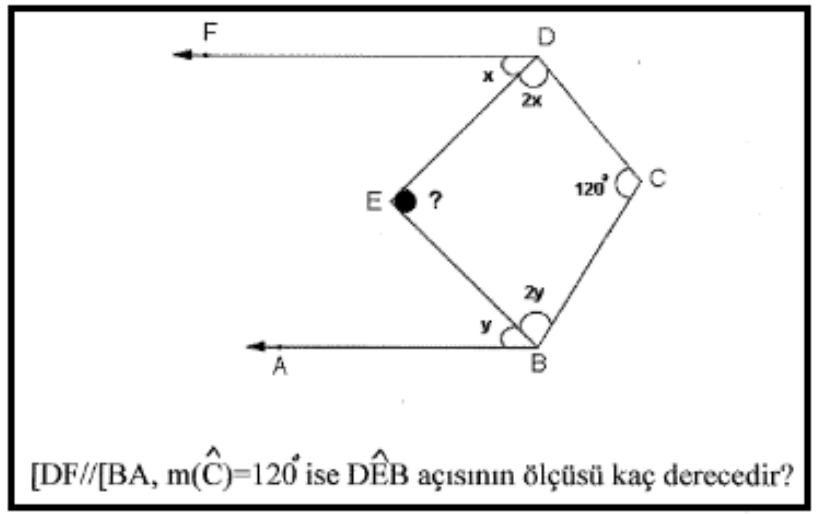

Figure 4. The $4^{\text {th }}$ Question 
In this question, students were expected to use their knowledge about "parallelism" and "the sum of interior angles of a quadrilateral is $360^{\circ}$ ". Table 7 presents the distribution of the answers given by students to the $4^{\text {th }}$ question among the categories of "correct", "incorrect", and "no solution" as well as percentages based on the number of students.

Table 7. The Evaluation of Student Solutions for the $4^{\text {th }}$ Question

\begin{tabular}{|c||c||c||c|}
\hline Question & CORRECT & INCORRECT & NO SOLUTION \\
\hline $\begin{array}{c}\text { The Number of } \\
\text { Students }\end{array}$ & 11 & 13 & 6 \\
\hline$\%$ & $37 \%$ & $43 \%$ & $20 \%$ \\
\hline \multicolumn{3}{|c|}{} \\
\hline \multicolumn{3}{|c|}{ ("Percentages are approximate values.) }
\end{tabular}

According to the table 4, 43\% of students solved this question wrongly. Based on the examination of the incorrect answers given, it was realized that students i) detected some geometric properties of the figure, but failed to associate these properties with other knowledge required for solution, and ii) generalized a property that was valid for only a specific condition over different situations (overgeneralization)

To make the mistakes made by students clearer, the above-mentioned findings and 2 sample student solutions about each finding are presented in table 8 .

Table 8. The analysis of the wrong solutions observed in the $4^{\text {th }}$ question

\begin{tabular}{|c|c|c|c|}
\hline Findings & $\begin{array}{l}\text { Wrong solution examples supporting the } \\
\text { findings }\end{array}$ & Comment & Students \\
\hline $\begin{array}{c}\text { S/he } \\
\text { generalizes } \\
\text { a property } \\
\text { that is valid } \\
\text { for only a } \\
\text { specific } \\
\text { condition } \\
\text { over } \\
\text { different } \\
\text { situations } \\
\text { (overgeneral } \\
\text { ization). }\end{array}$ & (A) & $\begin{array}{l}\text { They thought that the } \\
\text { opposing angles were } \\
\text { equal in the } \\
\text { quadrilateral DEBC. In } \\
\text { other words, they } \\
\text { wrongly assumed that } \\
\text { the aforesaid property } \\
\text { which was normally } \\
\text { unique to special } \\
\text { quadrilaterals was valid } \\
\text { for all quadrilaterals. (In } \\
\text { addition, they were able } \\
\text { to detect the } \\
\text { quadrilateral DEBC in } \\
\text { the figure, but failed to } \\
\text { associate it with other } \\
\text { knowledge required for } \\
\text { solution.) }\end{array}$ & $\begin{array}{l}\mathrm{S}_{2}, \mathrm{~S}_{3}, \mathrm{~S}_{6}, \mathrm{~S}_{7} \\
\mathrm{~S}_{12}, \mathrm{~S}_{13}, \mathrm{~S}_{14}\end{array}$ \\
\hline
\end{tabular}




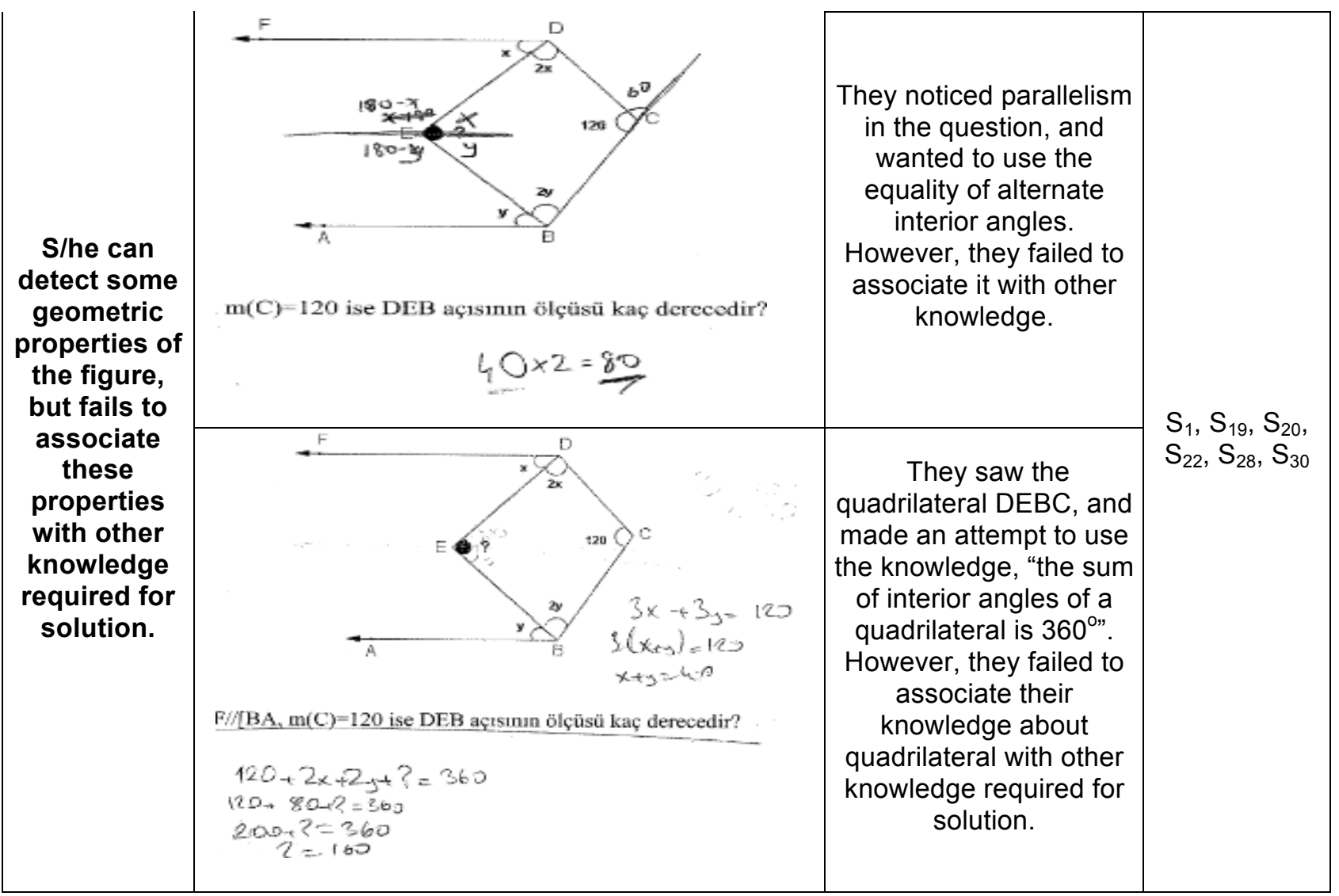

As can be seen in the figure 3 and figure 4 , the $3^{\text {rd }}$ and the $4^{\text {th }}$ questions were similar, thus similar knowledge should be used for solving them. Based on the examination of the answers given by students to these questions, it was seen that the students giving incorrect answers to the $3^{\text {rd }}$ question gave similar incorrect answers to the $4^{\text {th }}$ question, or left that question unanswered.

With the questions above, it was seen that students did not know what the third line intersecting two parallel lines meant, they detected some geometric properties of the figure, but failed to associate these properties with other knowledge required for solution, and they generalized a property that was valid for only a specific condition over different situations (overgeneralization). The fact that the same students made the same mistakes in similar questions demonstrates that they had misconceptions on those subjects.

\section{Conclusion and Implications}

The solutions provided by the $8^{\text {th }}$ grade students to 4 open-ended questions prepared for this study were examined in order to determine the mistakes and the misconceptions of students about the subject of "angles in geometry", which was one of the fundamental subjects of geometry. The reasons and the misconceptions leading to mistakes among students were almost the same in questions similar to one another.

Based on the examination of the student solutions for the $1^{\text {st }}$ and the $2^{\text {nd }}$ questions asked to students (they were similar questions requiring the use of almost the same knowledge for solution), it was seen that the main reason for mistakes in these question was about visualization - the first one among the levels of geometric understanding suggested in the Van Hiele model. At this level, students focus only on the physical appearances of geometric figures, and perceive geometric figures as a whole. They cannot recognize the geometric properties of figures. Th e most important feature of the Van Hiele model is that it explains the development of geometric thinking with five related levels. Each of these five levels defines the thinking processes used in geometric context. These levels define how they think and what kind of geometric ideas they are busy with instead of how much knowledge they have (Van de Walle, 2004).

Based on the examination of the student solutions for the $3^{\text {rd }}$ and the $4^{\text {th }}$ questions asked to students (they were similar questions requiring the use of almost the same knowledge for solution), it was 
seen that the main reason for mistakes in these questions was about analysis - the second one among the levels of geometric understanding suggested in the Van Hiele model. At this level, students detect the geometric properties of figures, but perceive these properties independently. They cannot associate such properties with one another. In addition, the examination of student solutions for the $4^{\text {th }}$ question reveals that students assumed that the equality of opposing angles, which was true for only the special quadrilaterals, was true for all quadrilaterals. In other words, students generalized a property that was valid for only a specific condition over different situations.

In addition to what is mentioned above, the mistakes made in all questions demonstrated that students had misconceptions on the subject of "parallelism". According to the findings and results of this study, students prefer to learn by rote when they fail to understand the logic of situations concerning geometric properties. However, they forget the knowledge acquired by rote learning in a short span of time. This creates trouble for teaching geometry where subjects are strictly linked to one another. Teachers play an important role in removing the misconceptions held by students. The mistakes and misconceptions of students should be determined and eliminated before they lead to any mistake in the learning of subjects to be covered in the future. In this respect, the logical bases of the properties of figures should be emphasized during the teaching of geometric figures. Students should be prevented from learning by rote. Furthermore, questions in which different figures are used should be preferred in the subjects of the same category so that students can feel the relations among different subjects in geometry.

\section{References}

Alkan, H., Altun, M. (1998). Mathematics Teaching, Anadolu Üniversitesi Açık Öğretim Fakültesi Yayınları, Eskişehir.

Baki, A., Kartal, T. (2004). The Characterization of Algebra Knowledge among High School Students in the Context of Conceptual Knowledge and Procedural Knowledge. Türk Eğitim Bilimleri dergisi, volume 2, issue 1, 27-50.

Baykul, Y. (1999). Mathematics Teaching in Primary Education, Anı Yayıncılık, 3rd Extended Edition, Ankara, 342.

Clements, D. H. \& Battista, M. T. (1992). Geometry and spatial reasoning. In D. Grouws (Ed.). Handbook of Research on Mathematics Teaching and Learning, (pp. 420-464). Reston, VA: National Council of Teachers of Mathematics.

Gilbert, J.K., Osborne, R.J., Fensham, P.J., Children's Science and Its Consequences for Teaching. Science Education. V.66, N.4, 1982: 623-633.

Karasar, N. (1995). Bilimsel Araştırma Yöntemi (Scientific Research Merhod) (7th Edition). 3A Araştırma Eğitim Danışmanlık Ltd.

Kopelman, E. "Invisible angles and visible parallels which bring deconstruction to geometry". Proceedings of the 20th International Conference for Psychology of Mathematics Education, University of Valencia: Spain, 185-192 (1996).

Matos, J.M. "Cognitive models of the concept of angle". Proceedings of the 18th International Conference for psychology of Mathematics Education, University of Lisbon: Portugal, 263-270 (1994).

Mayberry, J. W. (1983). The van Hiele levels of geometric thought in undergraduate preservice teachers. Journal for Research in Mathematics Education. 14, $58-69$.

Miles, M. B. \& Huberman, A. M. (1994). Qualitative data analysis: An expanded sourcebook (2nd ed.), London \& Thousand Oaks, California: Sage.

Mitchelmore, M. C. (1997). Children's Informal Knowledge of Physical Angle Situations. Cognition and Instruction, 7 (1) 1-19.

National Council of Teachers of Mathematics (NCTM) (1989). Curriculum and Evaluation Standards for School Mathematics. Reston, Va.: NCTM.

NCTM (2000). Principles and Standards for School Mathematics. Reston, Va. NCTM.

Prescott, A., Mitchelmore, M., \& White, P. (2002). Students' Difficulties in Abstracting Angle Concepts from Physical Activities with Concrete Material. In the Proceedings of the Annual Conference of the Mathematics Education Research Group of Australia Incorporated Eric Digest ED 472950).

Thirumurthy, V. (2003). Children's Cognition of Geometry and Spatial Reasoning: A Cultural Process. Unpublished PhD Dissertation, State University Of New York At Buffalo, USA.

Van de Walle, J. A. (2004). Elemantary and middle school mathematics. Fifth Edition, Virginia Common Wealth University.

Van Hiele, P.M.,\& van Hiele-Geldof, D. (1958). "A method of initiation into geometry". In H. Freudental (Ed.), Report on Methods of Initiation into Geometry, Groningen

Van Hiele -Geldof, D. (1984). The Didactics of Geometry in the Lowest Class of Secondary School. In David Fuys, Dorothy Geddes, and Rosamond Tischler (Eds.,), English Translation of Selected Writings of Dina van Hiele-Geldof and Pierre M. van Hiele, ERIC Document Reproduction Service, no. ED 287697.

Van Hiele, P. M. (1986). Structure and Insight. New York: Academic Press.

Yılmaz, S., Keşan, C., Turgut, M., Kabakçı, D. (2005). The Effect of Concept Map-Supported Problem-Solving Centered Geometry Teaching on the Van Hiele Geometric Thinking Levels of the 7th Grade Students. 14th National Educational Sciences Congress, Pamukkale University Faculty of Education, Denizli. 